\title{
Effect of pectin on jejunal glucose absorption and unstirred layer thickness in normal man
}

\author{
B FLOURIE, N VIDON, CH FLORENT, AND J J BERNIER \\ From the Hôpital Saint-Lazare, Paris, France
}

SUMmaRY The effect of high methoxy apple pectin, a carbohydrate gelling agent, on the intestinal absorption of glucose, water, and sodium was studied in man. The effect of intraluminal fibre was evaluated in 22 healthy volunteers by the intestinal perfusion technique under an occlusive balloon. The test solutions $(\mathrm{NaCl} 130 \mathrm{mM}, \mathrm{KCl} 5 \mathrm{mM}$, glucose or mannitol $30 \mathrm{mM}$, PEG $40005 \mathrm{~g} / \mathrm{l}$ ) were perfused just beyond the ligament of Treitz at a rate of $10 \mathrm{ml} / \mathrm{min}$. A $25 \mathrm{~cm}$ segment was studied. Three concentrations of pectin were tested: 6,10 , and $15 \mathrm{~g} / 1$. The effect of this pectin at two concentrations, 6 and $10 \mathrm{~g} / \mathrm{l}$, on the jejunal unstirred layer thickness was evaluated in nine other healthy subjects by an electrical technique. In mannitol solution, pectin reversed water and sodium absorption, whatever its concentration was, while in glucose solution it significantly reduced absorption of water and sodium at 10 and $15 \mathrm{~g} / 1$ only $(\mathrm{p}<0 \cdot 01)$. It significantly reduced glucose absorption at all concentrations $(p<0 \cdot 01)$. This reduction was found to be correlated with the solution viscosity $(p<0.01)$. Pectin did not alter the glucose dependent sodium transport but increased significantly $(\mathrm{p}<0.001)$ the unstirred layer thickness. These results suggested that, in healthy man, pectin acutely given may impair intestinal absorption by means of an increased unstirred layer resistance. This effect could contribute to the diminished postprandial glycaemia observed in human subjects fed pectin.

Different gelling agents of vegetable origin improve glucose tolerance test by reducing the peak of postprandial glycaemia and by preventing late hypoglycaemia in both normal subjects ${ }^{1}$ and diabetic patients. ${ }^{2-4}$ Several factors may influence the level of glycaemia after an oral load of glucose: rate of gastric emptying, rate of intestinal absorption, hormonal gastrointestinal responses, hormonal pancreatic response, hepatic glucose balance, and cellular metabolism of glucose.

As viscous fibres are unabsorbable substances, ${ }^{5}$ it is reasonable to assume that they may only act directly on the first three factors: rate of gastric emptying, intestinal absorption, and also hormonal gastrointestinal responses. The magnitude of postprandial hyperglycaemia in man after test meals containing absorbable and unabsorbable carbohydrates has been shown to be related to the viscosity of the substances, ${ }^{6}$ but the effect of increasing meal viscosity on gastric emptying and on

\footnotetext{
Address for correspondence: Miss N Vidon, INSERM U54, Hôpital SaintLazare, 107 rue du faubourg, Saint-Denis, 75010 Paris, France.

Received for publication 18 November 1983
}

intestinal glucose absorption is yet unknown. Holt $e t$ $\mathrm{al}^{7}$ have shown, in an acute study, that relatively large doses of guar gum (16 g/meal) and pectin (10 $\mathrm{g} / \mathrm{meal}$ ), in $400 \mathrm{ml}$ orange juice containing ${ }^{113 \mathrm{~m}} \mathrm{In}$ diethylene triamine penta-acetic acid as a nonabsorbable marker, markedly reduce the rate of gastric emptying in normal man, suggesting that this alteration in emptying may account for the reduction of glucose absorption. Moreover, chronic pectin supplementation ( $20 \mathrm{~g} / \mathrm{day} / 4$ weeks) markedly slows gastric emptying of a $100 \mathrm{~g}$ carbohydrate solid meal surface-labelled with ${ }^{99 \mathrm{~m}}$ Technetium sulphur colloid in normal volunteers. ${ }^{89}$ The direct effect of gel fibres on intestinal glucose absorption has not been shown so far in man and experiments in rats gave conflicting results: in in vitro investigation using everted sacs of rat jejunum, carbohydrate gelling agents were found to reduce intestinal glucose absorption. This inhibition was correlated with the incubation medium viscosity which is a function of the polysaccharide concentration alone ${ }^{10}$ and was probably brought about by an increased effectiveness of the mucosal diffusion barrier. ${ }^{11}$ In rat perfused jejunal 
loops, however, Schwartz and Levine ${ }^{12}$ showed that intraluminal pectin ( $1 \%$ weight/volume) did not modify intestinal glucose absorption.

In the present study, we have directly investigated the effect of pectin on human jejunal unstirred layer and on glucose, water and sodium transport by using an intestinal perfusion technique which avoids the influence of gastric emptying on nutrient absorption rate. We used different concentrations to ascertain whether its effect was dose dependent and therefore viscosity dependent.

\section{Methods}

\section{SUBJECTS}

\section{Effect of pectin on intestinal transport}

Studies were performed on 22 healthy volunteers who gave informed consent after an explanation of the protocol.

Experiments were carried out over a three day period. On the first day, the subjects were intubated with a multilumen tube. Intestinal perfusion studies were performed during days two and three, only one pectin concentration being tested per day.

The subjects ate every day. The first day, they received two meals. The second day, they also ate two meals after perfusion. The third day they went home. Meal composition was eggs, mashed potatoes, rusks, soft white cheese, and cream dessert. Perfusions were performed after about 12 hours fasting.

We used the technique of intestinal perfusion described by Modigliani and Bernier. ${ }^{13}$ The perfusion point, checked radiologically, was at the ligament of Treitz, under an occlusive balloon. A $25 \mathrm{~cm}$ segment was studied. The fluid was perfused at $37^{\circ} \mathrm{C}$ at a rate of $10 \mathrm{ml} / \mathrm{min}$.

Each solution was perfused for 80 minutes (a 50 minute equilibration period and three 10 minute collections). Perfusion of pectin was preceded by a similar perfusion of a control solution (of the same composition without pectin). For each day, subjects had perfusion with mannitol and/or glucose solutions given in random order without interval between them; their repartition in each group is stated in Table 1 . Test solutions were isotonic to plasma. The A solution contained $\mathrm{NaCl} 130 \mathrm{mM}$, $\mathrm{KCl} 5 \mathrm{mM}$, mannitol $30 \mathrm{mM}$, polyethylene glycol 4000 (PEG) $5 \mathrm{~g} / \mathrm{l}$, as a water soluble non-absorbable marker. In $B$ solution, mannitol was replced by glucose at the same concentration. In the $\mathrm{A}^{\prime}$ and $\mathrm{B}^{\prime}$ solutions, pectin was added at different concentrations of 6,10 , and $15 \mathrm{~g} / \mathrm{l}$. Pectin was a high methoxy pectin type 'brun NF pomme', batch no 2509 (Unipectine Laboratory, Paris, France) (mol wt 120000 , methoxy content $73.6 \%$ ). Solutions $A^{\prime}$
Table 1 Number of subjects perfused with mannitol and glucose solutions (with and without pectin) for the three concentrations tested

\begin{tabular}{llll}
\hline & \multicolumn{3}{l}{ Pectin concentration } \\
\cline { 2 - 4 } & $6 \mathrm{~g} / \mathrm{l}$ & $10 \mathrm{~g} / \mathrm{l}$ & $15 \mathrm{~g} / \mathrm{l}$ \\
\hline Number of subjects & 7 & 11 & 7 \\
$\begin{array}{l}\text { Glucose solution } \\
\text { Mannitol solution }\end{array}$ & 9 & 10 & 9 \\
Total subjects: 22 & & & \\
\hline
\end{tabular}

and $\mathrm{B}^{\prime}$ were prepared just before the beginning of infusion and agitated on a magnetic stirrer until pectin complete dissolution.

In perfused solutions and in each intestinal sample, PEG was measured by the turbidimetric method of Hyden, ${ }^{14}$ sodium by flame photometry, glucose by Technicon Autoanalyser and viscosity by a Cannon Fenske capillary viscometer. In vitro, pectin did not modify PEG concentrations. Absorption rates were calculated according to the usual formula. ${ }^{15}$

\section{Effect of pectin on jejunal unstirred layer}

An electrical technique has been described by Read $^{16}$ for measuring in situ the unstirred layer thickness in the human jejunum. The transmural potential difference was measured between an electrode situated in the intestinal lumen bathing in the solution and a subcutaneous reference electrode. The reference electrode was a plastic cannula filled with saline and inserted under the skin of the forearm. These electrodes were connected via agar salt bridges to the input terminals of a battery powered electrometer, the output of which was recorded on a chart recorder.

Nine healthy volunteers were studied. After an overnight fast, a double lumen radio-opaque tube was swallowed and positioned in the upper part of jejunum, within $15 \mathrm{~cm}$ of the duodenojejunal flexure. An intramuscular injection of propantheline bromide (Pro-banthine, Searle) given just before the start of the infusions, abolished the spontaneous fluctuations in potential difference associated with intestinal motility.

Each subject received the six solutions listed in Table 2. They were infused at a steady state of 5 $\mathrm{ml} / \mathrm{min}$ and were continuously siphoned at the same rate from the site of infusion. This, together with the effect of propantheline, enhanced the stability of the electrical record.

The infusion of solution 1 was continued until a stable baseline had been maintained for at least 10 minutes. Subsequently infusion of solution 2 , which 
Table 2 Solutions infused into jejunal lumen to measure the potential difference in nine subjects

\begin{tabular}{llcl}
\hline Solution & $\begin{array}{l}\text { Sodium } \\
\text { chloride } \\
(m M)\end{array}$ & $\begin{array}{l}\text { Mannitol } \\
(\mathrm{mM})\end{array}$ & $\begin{array}{l}\text { Pectin } \\
(\mathrm{g} / \mathrm{l})\end{array}$ \\
\hline 1 & 154 & 0 & 0 \\
2 & 104 & 100 & 0 \\
$1^{\prime}$ & 154 & 0 & 6 \\
$2^{\prime}$ & 104 & 100 & 6 \\
$1^{\prime \prime}$ & 154 & 0 & 10 \\
$2^{\prime \prime}$ & 104 & 100 & 10 \\
\hline
\end{tabular}

contained a lower concentration of sodium chloride than solution 1 , created a diffusion gradient for sodium chloride. The measurement of the half time for the attainment of this diffusion potential was used to estimate the thickness of the unstirred layer by the method of Diamond ${ }^{17}$ :

$$
d^{2}=\frac{t_{1} D}{0 \cdot 38}
$$

where $d$ is the unstirred layer thickness, $t_{\frac{1}{2}}$ the half time for the development of the diffusion potential difference, and $\mathrm{D}$ the diffusion coefficient for 125 $\mathrm{mM}$ sodium chloride in free solution $\left(12.4 \times 10^{-6}\right.$ $\left.\mathrm{cm}^{-2} / \mathrm{s}\right)$. After return to solution 1 , the diffusion potential produced by pectin solutions was recorded. In all subjects the sequence of perfusion was in increasing concentration of pectin. After each solution 2 there was a return to the solution 1 before proceeding to the next pair. Time to obtain a stable base line after solution $2^{\prime}$ was $3 \cdot 4 \pm 1 \cdot 2$ (mean $\pm S E M)$ minutes and $5 \cdot 7 \pm 2 \cdot 3$ (mean $\pm \mathrm{SEM}$ ) minutes after solution $2^{\prime \prime}$.

\section{STATISTICAL ANALYSIS}

Data are expressed as mean \pm SEM. The Student's $t$ test, for paired and non-paired series when appropriate, Wilcoxon's matched pair test and correlation analysis were used for statistical comparisons.

\section{Results}

Pectin is a component of dietary fibre; it is resistant to degradation by digestive enzymes and is not absorbed by the small intestine. ${ }^{5}$

We calculated the concentration ratio of pectin and PEG 4000 in test solutions, and the same ratio in samples. The mean difference between the two ratios was $+3.3 \%$. This change was not statistically significant. Moreover, in vitro, pectin did not modify PEG concentrations. So we may consider that the perfused solutions remained homogenous in the small bowel lumen. Viscosity of the perfused solution increased exponentially with pectin concentration in solution (Fig. 1).

A 50 minute equilibration period was sufficient to obtain an adequate washout after the first pectin solution. Indeed, sample viscosity returned to basal values. Moreover water and $\mathrm{Na}$ movements were similar in the three samples and comparable to values usually obtained with these control solutions when they were perfused in human jejunum. At last, control values ( $\mathrm{Na}$ and water movements) were similar when A or B solutions were given first or second.

\section{EFFECT OF PECTIN ON NET WATER MOVEMENTS}

(Fig. 2)

There was no difference in net water movements when we perfused the control solution of the three sets of experiments; net absorption of water occurred with both mannitol and glucose control solutions. When pectin is added to the mannitol solutions, it significantly reversed the small net absorption into a net water secretion. Pectin had the same effect whatever its concentration in the perfused solutions was. The significant reduction of water absorption was similar when concentration of pectin in glucose solution was either 10 and $15 \mathrm{~g} / \mathrm{l}$ while this reduction was not statistically significant when pectin concentration was $6 \mathrm{~g} / 1$.

\section{EFFECT OF PECTIN ON NET SODIUM MOVEMENTS} (Fig. 3)

There was no difference in net sodium movements when we perfused the control solutions of the three sets of experiments. With mannitol solution, pectin significantly reversed net absorption into a net secretion. It had the same effect whatever its

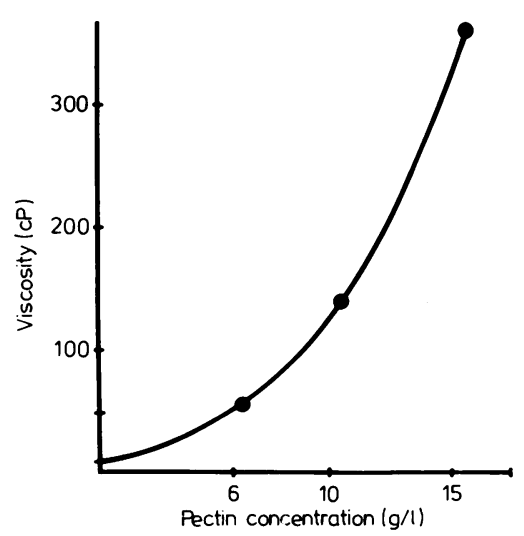

Fig. 1 Standard curve: viscosity in centipoises $=f($ pectin concentration in $g / l$ ). 


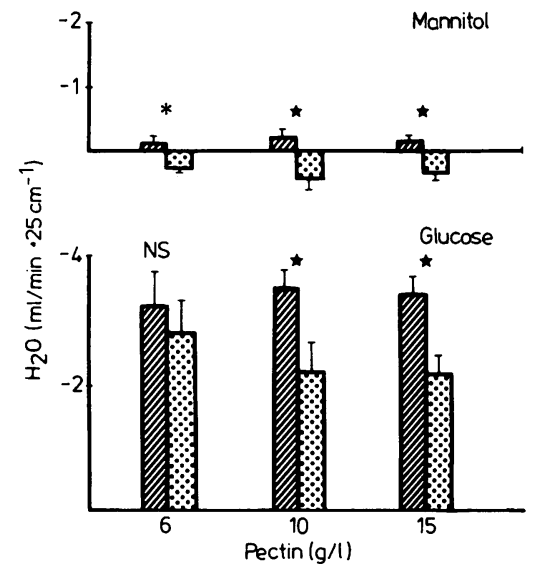

Fig. 2 Effect of pectin on net water movements during intestinal perfusion. Water movements during perfusion of $(A)$ mannitol solution, $(B)$ glucose solution, without ( $A$ and $B) \mathscr{Q}$, and with pectin $\left(A^{\prime}\right.$ and $\left.B^{\prime}\right)$ concentrations of pectin $(6,10$, and $15 \mathrm{~g} / \mathrm{l})-=$ means absorption, $+=$ secretion, $N S=$ not significant, ${ }^{\star} p<0.01,{ }^{*} p<0.05$.

concentration in the perfused solutions.

Presence of pectin at concentration of either 10 or $15 \mathrm{~g} / \mathrm{l}$ in glucose solution significantly reduced the absorption of sodium, while this effect was not statistically significant when its concentration was $6 \mathrm{~g} / \mathrm{l}$.

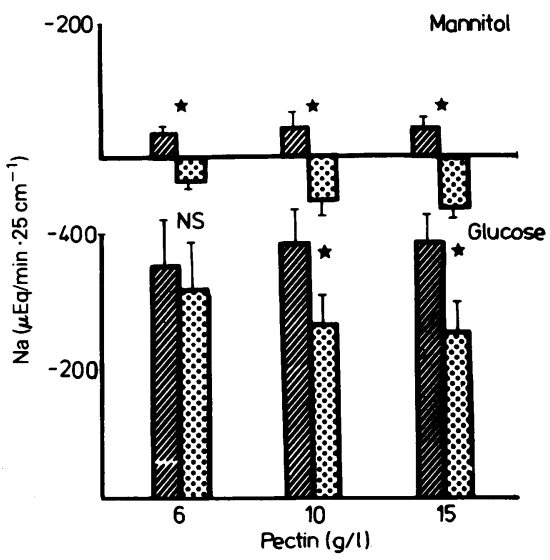

Fig. 3 Effect of pectin on net sodium movements during intestinal perfusion. Sodium movements during perfusion of $(A)$ mannitol solution, $(B)$ glucose solution, without $(A$ and $B) \mathbb{Q}$, and with pectin $\left(A^{\prime}\right.$ and $\left.B^{\prime}\right)$ concentrations of pectin $(6,10$, and $15 \mathrm{~g} / \mathrm{l})-=$ means absorption, $+=$ secretion, $N S=$ not significant, $\star p<0.01$.
EFFECT OF PECTIN ON NET GLUCOSE MOVEMENTS Glucose absorptions were similar during perfusion of the control solutions. They were reduced when pectin was in the solution (Fig. 4); this statistically significant reduction depended upon the pectin concentration. The percentage of inhibition of glucose absorption was $10,13 \cdot 6$, and $23 \cdot 8 \%$ for 6 , 10 , and $15 \mathrm{~g}$ pectin respectively.

Figure 5 shows the decrease in net glucose absorption (expressed as per cent of glucose absorption) in relation to the viscosity of the perfused solution. The results indicate that the lesser glucose absorption is linearly related to solution viscosity depending itself on pectin concentration $(\mathrm{p}<0.01)$.

Pectin did not modify the glucose dependent sodium transport (Table 3) at the sodium and glucose tested concentration $(\mathrm{Na} 130 \mathrm{mEq} / \mathrm{l}$, glucose $30 \mathrm{mM})$. For each subject who received both mannitol and glucose solutions, the glucose dependent sodium was calculated using the formula:

$$
\frac{\mathrm{Na}_{\mathrm{g}}-\mathrm{Na}_{\mathrm{m}}}{\mathrm{G}_{\mathrm{a}}}
$$

$\mathrm{Na}_{\mathrm{g}}$ and $\mathrm{Na}_{\mathrm{m}}$ being the sodium absorbed during perfusion of glucose and mannitol solutions respectively and $G_{a}$ the absorbed glucose.

\section{EFFECT OF PECTIN ON UNSTIRRED LAYER}

THICKNESS

Table 4 shows the jejunal unstirred layer thickness estimated from measurements of generation half time of diffusion potential difference when pectin was, or was not, in perfused solution.

The results showed that the enlargement of the apparent unstirred layer thickness was statistically significant when pectin was added in perfused

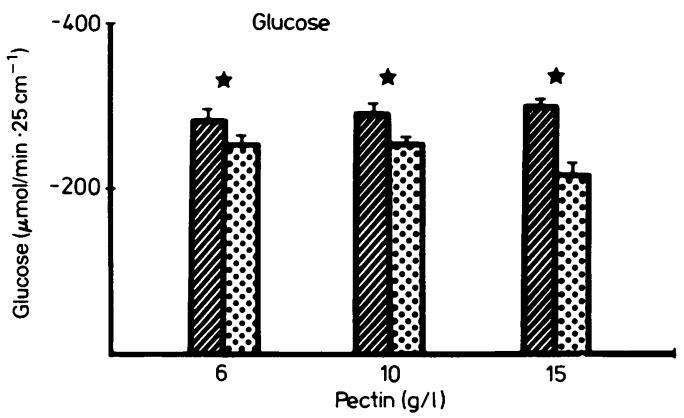

Fig. 4 Effect of pectin on net glucose movements during intestinal perfusion. Glucose absorption during perfusion of solutions without and with pectin at three different concentrations $(6,10$, and $15 \mathrm{~g} / \mathrm{l})-=$ means absorption, $\star p<0.01$. 
solution. There was a linear relation between logarithm of this unstirred layer thickness and pectin concentration $(r=0.96, p<0.001)$.

\section{Discussion}

These results show, for the first time, that in healthy man pectin acutely given reduces water, sodium and glucose intestinal absorption. It does not modify the glucose dependent sodium absorption at the sodium and glucose tested concentration. An equal effect of pectin on both the glucose and $\mathrm{Na}$ absorption could explain that the glucose dependent $\mathrm{Na}$ transport remains unaltered. At pectin concentration of $6 \mathrm{~g} / 1$, however, pectin did not cause an equal effect as $\mathrm{Na}$ movements are not affected by fibre while glucose absorption is significantly reduced. The diminished glucose absorption is less likely to be because of a modification of the absorbing cell membrane itself than to a decrease of the intraluminal diffusion of glucose.

These results are not in agreement with those of Schwartz and Levine ${ }^{12}$ who showed in rat perfused jejunal loop that pectin $(10 \mathrm{~g} / \mathrm{l})$ did not impair intestinal glucose absorption. The effects of chronic supplementation in fibre on intestinal glucose absorption were also conflicting, according to whether experiments were carried out in animal or man. Schwartz and Levine ${ }^{12}$ have observed, in rats which were studied after a fibre free diet supplemented with $5 \%$ pectin five weeks ingestion, a decrease of the intestinal glucose absorption. They suggested that chronic fibre ingestion could have altered the intestinal membrane or the microvilli without inducing changes in the morphologic parameters. These authors, ${ }^{9}$ perfusing glucose solution without pectin in fasted patients after they were placed on a low fibre $(3 \mathrm{~g})$ diet for two weeks, followed by four weeks of an isocaloric diet supplemented with $20 \mathrm{~g} /$ day of apple pectin have observed that pectin did not impair intestinal absorption of glucose.

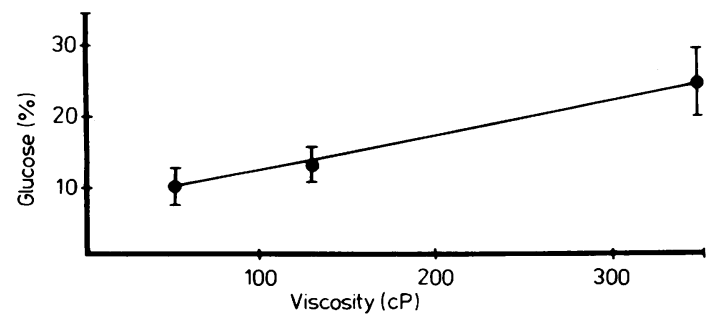

Fig. 5 Correlation between percentage of inhibition of glucose absorption and solutions viscosity (expressed in cP). $p<0.01$.
Table 3 Glucose dependent Na transport without and with pectin at concentrations of 6,10 , and $15 \mathrm{~g} / \mathrm{l}$ during intestinal perfusion

\begin{tabular}{llll}
\hline & & \multicolumn{3}{l}{$\begin{array}{l}\text { Glucose dependent Na } \\
\text { transport }\end{array}$} \\
\hline Pectin & $\begin{array}{l}6 \mathrm{~g} / 1 \\
\mathrm{n}=7\end{array}$ & $\begin{array}{l}10 \mathrm{~g} / \mathrm{l} \\
\mathrm{n}=9\end{array}$ & $\begin{array}{l}15 \mathrm{~g} / 1 \\
\mathrm{n}=7\end{array}$ \\
\hline With pectin & $1 \cdot 28 \pm 0 \cdot 21$ & $1 \cdot 33 \pm 0 \cdot 22$ & $\begin{array}{l}1 \cdot 56 \pm 0 \cdot 21 \\
\text { Without pectin }\end{array}$ \\
\hline
\end{tabular}

Mean \pm SEM. NS $=$ not significant.

This should confirm the results obtained in the second part of our study that the pectin effect on glucose absorption is linked to the intraluminal viscosity induced by pectin but not to intestinal mucosa alterations.

Moreover, on incubation of rings of everted rat small intestine, Elsenhans et al Johnson and Gee, ${ }^{11}$ have shown that inhibition of intestinal absorption was correlated with the incubation medium viscosity which depends only on the polysaccharide concentration and is independent of the other properties of the carbohydrate gelling agents. A medium viscosity increase gives rise to a thickening of the unstirred layer.

The pectin gel itself may decrease the diffusion coefficient of the molecule studied. We assumed that there is no interaction between the solute and the polymer and that the diffusing molecule is small in relation to the intersegmental distance of the lattice. Using Mackie and Meares' formula ${ }^{18}$ the diffusion coefficient will be reduced by $4 \%$ in a gel having $1 \%$ polymer volume. We have ignored this effect in calculating the apparent unstirred layer thickness because of the low concentrations of pectin used. We found in man an enlargement of the apparent unstirred layer thickness linked to the viscosity, thus to pectin concentration. The more the viscosity solution increases, the more the unstirred layer thickness is important and the less the glucose absorption is. Viscosity and thickness of the unstirred layer increase exponentially with the

Table 4 Jejunal unstirred layer thickness when solution, without and with pectin, was perfused at $5 \mathrm{ml} / \mathrm{min}$

\begin{tabular}{ll}
\hline $\begin{array}{l}\text { Pectin concentration } \\
(\mathrm{g} / \mathrm{l})\end{array}$ & $\begin{array}{l}\text { Unstirred layer thickness } \\
(\boldsymbol{\mu} \mathrm{m})\end{array}$ \\
\hline 0 & $667 \pm 33$ \\
6 & $1219 \pm 48$ \\
10 & $1873 \pm 73$ \\
\hline
\end{tabular}

Mean \pm SEM. $\mathrm{n}=9$. 
pectin concentration. Thus it seems likely that pectin is able to reduce the intraluminal diffusion of solute so it reduces glucose and electrolyte diffusion to the enterocyte apical pole.

From these data may be suggested a general picture of pectin effect on the human digestive tract: (a) pectin delays gastric emptying by a yet discussed mechanism; $;^{7-9} 19-21$ (b) pectin impairs intestinal glucose absorption by increasing intraluminal unstirred layer viscosity and thickness; and (c) it is known by hydrogen breath test (indicator of the colic fermentation of the unabsorbed glucose) and by plasma and urine xylose measure, after a xylose test, that viscous agents do not modify the total intestinal glucose absorption. ${ }^{122} 23$

It is also established that viscous fibres increase the orocaecal transit time. ${ }^{62324}$ Thus, it may be proposed that glucose absorption remains complete within the small intestine but in a more greater length that may modify the hormonal responses. In our study small quantities of glucose $(30 \mathrm{mM}$ at 10 $\mathrm{ml} / \mathrm{min}$ during 80 minutes) were perfused; blood glucose concentrations were unaffected; so we did not study the induced hormonal responses.

It must be noted that pectin inhibitory effect on glucose intestinal absorption was observed when the intraluminal concentrations of pectin were smaller than those probably reached after therapeutical doses. As the acceptability of high pectin amounts in chronic indigestion is reduced by its bad palatibility, a lower dose could be enough for the treatment of some diabetic patients or of postgastrectomy digestive disturbances.

This work was supported by grant no 80.7.0211 from the Délégation Générale à la Recherche Scientifique et Technique.

\section{References}

1 Jenkins DJA, Leeds AR, Gassull MA, Cochet B, Alberti KGMM. Decrease in postprandial insulin and glucose concentrations by guar and pectin. Ann Intern Med 1977; 86: 20-3.

2 Jenkins DJA, Goff DV, Leeds AR et al. Unabsorbable carbohydrates and diabetes: decreased postprandial hyperglycaemia. Lancet 1976; 2: 172-4.

3 Gassull MA, Goff DV, Haisiman P et al. The effect of unavailable carbohydrate gelling agents in reducing the post-prandial glycaemia in normal volunteers and diabetics. J Physiol (Lond) 1976; 259: 52P-3P.

4 Miranda PM, Horwitz DL. High-fiber diets in the treatment of diabetes mellitus. Ann Intern Med 1978; 88: $482-6$.

5 Trowell HC. Crude fibre, dietary fibre and atherosclerosis. Atherosclerosis 1972; 16: 138-40.

6 Jenkins DJA, Wolever TMS, Leeds AR et al. Dietary fibres, fibre analogues, and glucose tolerance: importance of viscosity. Br Med J 1978; 1: 1392-4.

7 Holt S, Heading RC, Carter DC, Prescott LF, Tothill P. Effect of gel fibre on gastric emptying and absorption of glucose and paracetamol. Lancet 1979; 1: 636-9.

8 Levine RA, Schwartz SE, Singh A, Rogus JB, Track NS. Chronic pectin ingestion delays gastric emptying. [Abstract] Gastroenterology 1981; 80: 1211A.

9 Schwartz SE, Levine RA, Singh A, Scheidecker JR, Track NS. Substained pectin ingestion delays gastric emptying. Gastroenterology 1982; 83: 812-7.

10 Elsenhans B, Süfke U, Blume R, Caspary WF. The influence of carbohydrate gelling agents on rat intestinal transport of monosaccharides and neutral amino acids in vitro. Clin Sci 1980; 59: 373-80.

11 Johnson IT, Gee JM. Effect of gel-forming gums on the intestinal unstirred layer and sugar transport in vitro. Gut 1981; 22: 398-403.

12 Schwartz SE, Levine GD. Effects of dietary fiber on intestinal glucose absorption and glucose tolerance in rats. Gastroenterology 1980; 79: 833-6.

13 Modigliani R, Bernier JJ. Absorption of glucose, sodium and water by the human jejunum studied by intestinal perfusion with proximal occluding balloon and at variable flow rates. Gut 1971; 12: 184-93.

14 Hyden S. A turbidimetric method for the determination of high polyethylene glycols in biological materials. Ann R Agric Coll Uppsala 1956; 22: 139-45.

15 Whalen GH, Harris JA, Greenen JE, Soergel KH. Sodium and water absorption from the human small intestine. The accuracy of the perfusion method. Gastroenterology 1966; 51: 975-84.

16 Read NW, Barber DC, Levin RJ, Holdsworth CD. Unstirred layer and kinetics of electrogenetic glucose absorption in the human jejunum in situ. Gut 1977; 18: $865-76$

17 Diamond JM. A rapid method for determining voltage concentration relations across membranes. J Physiol (Lond) 1966; 183: 83-100.

18 Mackie J, Meares P. The diffusion of electrolytes in a cation-exchange resin membrane. I. Theoretical. Proc $R$ Soc 1955; 232A: 498-509.

19 Anderson JW, Midgley WR, Wedman B. Fiber and diabetes. Diabetes Care 1979; 2: 369-79.

20 Ralphs DNL, Lawaetz O, Brown NJG, Leeds AR. Effect of a dietary fibre on gastric emptying in dumpers. [Abstract] Gut 1978; 19: A986-7.

21 Leeds AR, Ralphs DN, Boulos P et al. Pectin and gastric emptying in the dumping syndrome. Proc Nutr Soc 1978; 37: A23.

22 Jenkins DJA, Gassull MA, Leeds AR et al. Effect of dietary fiber on complications of gastric surgery: prevention of post-prandial hypoglycaemia by pectin. Gastroenterology 1977; 73: 215-7.

23 Dilawari JB, Leeds AR, Gassull MA, Haisiman P, Jenkins DJA. The effect of dietary fibre (guar gum) on carbohydrate absorption. Gastroenterology 1977; 72: A 1049 .

24 Leeds AR, Gassull MA, Metz GL, Jenkins DJA. Food: influence of form on absorption. Lancet 1975; 2: 1213. 